\title{
Academic Accommodations: Perceptions, Knowledge and Awareness Among College Students without Disabilities
}

\author{
Adam H. Meyer ${ }^{1}$, Karen A. Myers ${ }^{2, *}$, Angela L. Walmsley ${ }^{2}$, Sarah E. Laux ${ }^{3}$ \\ ${ }^{1}$ Director, Holman Success Center, Disability Resource Center (DRC) and CATE Lab, Eastern Michigan University, Ypsilanti, Michigan, \\ 48197, USA \\ ${ }^{2}$ Department of Education, Saint Louis University, St. Louis, Missouri, 63103, USA \\ ${ }^{3}$ MA, Assistant Director, Civic Engagement, Southern Illinois University Edwardsville, Edwardsville, Illinois, 62026,USA
}

\begin{abstract}
The growing number of students with disabilities on college campuses leads to an increase in academic accommodations provided to students. So what is the reaction of students without disabilities toward those students who receive accommodations? The purpose of this study was to investigate how students without disabilities perceive the accommodation use of students with learning disabilities and attention deficit disorder in the college academic environment. Based on data analysis of 928 web-based surveys (of the 1,295 surveys submitted), perceptions of students without disabilities were mostly neutral and/or positive; however, limits to what was tolerated within the process did exist. Recommendations are offered for campus practices.
\end{abstract}

Keywords Accommodations, College Students, Disabilities

\section{Introduction}

Higher education support for students with learning disabilities began in the late 1970s and reached full advancement in the 1980s (as indicated in Stalcup\& Freeman[1] through Madaus[11]). Current traditional-age undergraduate students have spent their entire academic careers in education environments where academic accommodations always have been available and provided to students with disabilities, specifically to students with Attention Deficit Disorder and/or Attention Deficit Hyperactivity Disorder (ADD/ADHD) and other learning disabilities for the purpose of this study. Roughly, 93 percent of postsecondary institutions that enrolled students with disabilities provide forms of academic accommodation such as extended time for exams, alternative exam formats, and classroom note takers, to name a few[12]. As such, the concept and process of witnessing such accommodations is no longer new and, one can argue, that most current undergraduate students without disabilities openly accept the provision of academic accommodations as a known and understood practice available to students that qualify for such accommodations.

Given that the published literature references higher education support for students with learning disabilities beginning forty years ago, it is hypothesized that most

* Corresponding author:

kmyers11@slu.edu (Karen A. Myers )

Published online at http://journal.sapub.org/edu

Copyright (C) 2012 Scientific \& Academic Publishing. All Rights Reserved stu dents without disabilities accept provision of academic accommodations as a known practice available to select students who qualify. But how these students perceive the process in today's society is unknown due to scant information available from research.

The purpose of this study was to investigate the perceptions of college students without disabilities toward students with learning disabilities and attention deficit disorder. These perceptions were gauged by assessing the attitudes of higher education students without disabilities toward the academic accommodation process.

\section{Literature Review}

According to the Raue and Lewis in conjunction with the U.S. Department of Education[12], as of the 2008-2009 academic year, 88 percent of two- and four-year Title VI degree-granting postsecondary institutions reported enrolling students with disabilities. Further, a large percentage of institutions that enrolled students with disabilities during that same academic year reported enrolling students with specific learning disabilities (86 percent) and ADD/ADHD (79 percent). Specific learning disabilities made up 31 percent of disabilities reported by institutions, with ADD/ADHD following at 18 percent.

Since the implementation of the Rehabilitation Act of 1973[13] and the Americans with Disabilities Act in 1990[14], the process of providing academic accommodations to students with disabilities has become more established and rooted in the higher education culture. Due to the growing enrollments of students with disabilities 
in higher education, there is much increasing interest in research on accessibility of higher education for students with disabilities[15][16]. However, due to lack of available and current research on this topic, knowledge of students' perceptions of academic accommodations provided to students with disabilities is limited.

This lack of research proposes the question "How do traditional age undergraduate students without disabilities perceive students with $\mathrm{ADD} / \mathrm{ADHD}$ and other learning disabilities in the college academic environment when academic acco mmodations are utilized by students with such disabilities?" As such, the purpose of this study is to investigate the perceptions college students without disabilities have toward students with ADD/ADHD and other learning disabilities. These perceptions were specifically measured by assessing the attitudes of higher education students without disabilities toward the academic accommodation process. This concept of 'attitude' was “a disposition to respond favorably or unfavorable to an object, person, institution, or event"[17]. The terms 'attitudes' and 'perceptions' convey the same meaning throughout this research. 'Academic accommodations' refer to the carious academic supports granted by higher education campus disability service providers. Throughout this study, 'disability' signifies a clinical diagnosis of ADD/ADHD or other learning disorders.

ADD/ADHD and other learning disabilities are the largest collective disability group on many college campuses[18][19][12]. As such, students without disabilities are most likely to experience interactions with this particular cluster of students with such defined disabilities on a daily basis. Similarly, students with ADD/ADHD and other learning disabilities inevitably interact with their peers without disabilities, in an effort to fit into the college mainstream of academics and extracurricular activities. As a result of this 'effort to fit', students with disabilities are often hesitant to receive academic accommodations due to expressed apprehension concerned with how their peers without disabilities will perceive them[20].

The intention of academic accommodation provisions in higher education is to ensure that a student with a disability receives equal opportunity to demonstrate academic abilities by minimizing the impact of a disability of academic performance. This process seeks to provide access to success and lessen academic discrimination on the basis of one's disability[21]. Reasonable academic accommodations include, but are not limited to: extended time for exams, assistance in receiving class notes, taking an exam in a different room (aside from the classroom), audio-formatted course readings, sign language interpreters, handouts in an enlarged font, and technological devices to support students in reading and writing[21][19][22][23][5].

Students with disabilities do not wish to be perceived as being different or being defined by their disability[15]. The decision to utilize academic accommodations for students with ADD/ADHD or other learning disabilities is not approached lightly, specifically because of the hidden nature of such disabilities. It is often easier for a student with $\mathrm{ADD} / \mathrm{ADHD}$ or other learning disabilities to conceal his or her disability. However, individuals with physical disabilities utilizing wheelchairs, canes or guide dogs, or visible hearing aids, to name a few, are more likely to naturally and inevitably disclose their disability through daily interactions. Students with ADD/ADHD and other learning disabilities often must forego this choice of secrecy through disclosure to utilize academic accommodations [20]. Further, students with such easily concealed disabilities may not feel the need to conceal their disabilities to acquaintances. However, such concealment and disclosure will prove inevitable if classmates and acquaintances witness a student with a hidden disability receiving academic acco mmodations such as a note-taker or extra time for an exam.

Attitudinal studies over the past twenty years focusing on social and academic perspectives of students without disabilities toward individuals with disabilities examined gender, major, year in college, and level of contact with students with disabilities (for example, Fichten[24]; Lyons \& Hayes[25]; Yuker[26]; and Upton, Harper, \& Wadsworth[27] among others). Following the lead of previous scholars, this investigation sought to add to information in these sub-areas through the data collected. One additional demographic not identified in the literature but part of this investigation was higher education setting (private or public).

\section{Methodology}

\subsection{Participants}

For this particular research project, traditional age college students, specifically between the ages of 18 and 25, were selected as the target of interest. At the time of this study, a majority of the current traditional-age undergraduate students had spent their entire lives in an educational environment where academic accommodations were or should have been provided to students with disabilities. The omission of students age 26 or older was due largely to the possibility of such students' past academic experiences where accommodations may not have been part of the academic culture at the time when the student was enrolled in early childhood or elementary education programs. Further, the researchers provided concern that students age 26 or older may have had life experiences beyond that of a traditional-age full-time student, potentially influencing perceptions of the academic accommodation process.

Two Midwest higher education institutions were used for data collection sites. One institution, medium-sized, is a religiously-affiliated private college. The other, medium- to large-sized is public. At both universities, students were sent an email containing an active link directing them to the survey created for this project.* Approximately 7000 students at each university (14,000 students total) received an invitation to participate in the survey. It is important to note that the students at the private university were emailed the survey invitation during the second week of the semester. 
At the public university, students did not receive the survey invitation until the seventh week of the semester due to processing delays with obtaining access to the student email addresses. The researchers note this difference may have been the primary reason that substantially more students from the private university participated in the research than did students from the public university. By the time the public university students received the survey, it was the campus' midterm exam week and Spring Break week. Detailed demographic response data can be found in Table 1, Frequency Count (Percentage) of Responses by Demographic Category.

Table 1. Frequency Count (Percentage) of Responses by Demographic Category

\begin{tabular}{|c|c|}
\hline Gen der & Higher Education Setting \\
\hline Male --- 311 (33.5\%) & Private --- 710 (76.5\%) \\
\hline Female -- 617 (66.5\%) & Public --- 218 (23.5\%) \\
\hline Total -- 928 & Total -- 928 \\
\hline Year in School & $\begin{array}{c}\text { Level of Con tact with People } \\
\text { with Disabilities }\end{array}$ \\
\hline Freshman -- 259 (27.9\%) & Very Frequent, regular contact \\
\hline Sophomore --- 1823 (24.0\%)
\end{tabular}

During the time in which the survey was available, a total of 1245 students responded to the research questionnaire with 894 responses from the private institution (12.8\% response rate) and 351 responses from the public institution (5.0\% response rate). When organizing the survey, two population subsets were not considered in the final respondent pool: students with disabilities and students over the age of 25. Because any student with any disability may have biased attitudes toward students with similar disabilities and the academic accommodation process, the subject of this investigation, surveys from students indicating a disability diagnosis were not factored into the data analysis. For this project, a total of 162 students disclosed a disability and these responses were subsequently removed from the final survey count. Further, 134 students responded with a reported age of being 26 or older. These survey response sets were subsequently isolated in the database and removed. An additional 21 students only completed two or three of the demographic survey items, leading to these surveys being removed from the database. Thus, a total of 928 surveys were used in the final analysis.

\subsection{Survey}

Twenty-nine quantitative items were presented with a Likert scale (Cronbach's alpha $=.884$ ). Most of the items within the survey were in third-person or neutral format rather than in a first-person format. For example, "Students with LD or ADD who have high grade point averages (A or B averages) do not really need academic accommodations," was asked on the survey instead of "I believe students with LD or ADD who have high grade point averages (A or B averages) do not really need academic accommodations." This format was specifically chosen in an attempt to lessen the likelihood that some respondents might have sought to answer in a socially desirable manner, which could have influenced reported attitudes toward disability[28].

The researchers' intention of utilizing quantitative questions was to assess the attitudes of students without disabilities toward students with ADD/ADHD and other learning disabilities through two primary categories of survey items: 1) General Academic Accommodation Questions and Statements and 2) Specific Academic Accommodations. The first category of questions asked respondents to assess students with disabilities and the general use of accommodations. Questions and statements were organized into three subcategories of four or five survey items within each subcategory. The subcategories were as follows:

- Perceptions of Fairness of the General Accommodation Process (PFAP);

- Perceptions of Legitimacy of Need for Academic Accommodations (LNAA);

- Acceptance of Students Who Use Accommodations (ASA);

The second section of survey items, the Specific Academic Accommodation category, placed emphas is on the specific academic accommodations potentially available to students with ADD/ADHD and other learning disabilities in the college environ ment. This category was also broken into three parts with five to six survey items per section:

- Provision of Accommodations for the Exam Experience (PAE);

- Reasonableness of Accommodations in the Classroom Experience (RAC);

- Reasonableness of Special Accommodation Considerations in the Overall Academic Experience (RSCO).

These survey subcategories created the structure around which the data was ultimately analyzed and reported.

In addition to the quantitative questions, the survey incorporated one open-ended, qualitative question. The question given to the students was as follows: "Overall, what would you say is the general campus feeling/attitude of the 
academic acco mmodation process and/or the general campus feeling/attitude of students with learning disabilities or attention deficit disorder who use academic accommodations?” The purpose of the open-ended question was to capture a brief understanding regarding what students without disabilities thought about these two issues.

\subsection{Analysis Procedures}

For each of the five demographic categories - gender, year in college, major, level of contact, and institution type - six ANOVAs were conducted by assessing the variables identified within the demographic categories against the six subcategories in the survey. Following the quantitative analysis, the collective qualitative responses were organized and coded to identify themes that emerged from the collection of student replies. Of the 928 students whose responses were used in this research, 532 provided qualitative comments that directly answered the final research question.

To analyze the qualitative comments, the researchers separated responses into three broad categories: 1 ) responses that focused solely on academic accommodations; 2) responses that focused only on students with $\mathrm{ADD} / \mathrm{ADHD}$ and/or other learning disabilities; and 3) responses that offered information on both accommodations and students with disabilities. Once separated, these three major codes were divided into three subcodes of positive, negative, and neutral responses related to the major code. Once completed, the collective positive, negative, and neutral responses were further separated based on themes realized across the comments.

\section{Results}

\subsection{Quantitative Results}

ANOVA results from each survey demographic (Appendix A) are briefly discussed. Regarding the gender demographic, one-way ANOVAs were utilized to compare the six survey subsections against responses from males and females. Significant differences were identified within subsections of Perceptions of Fairness of the General Accommodation Process (PFAP) $(F(1,887)=24.552$, p $<.001, \mathrm{~h}^{2}{ }_{\mathrm{p}}=.027$, which reflects a small effect size[29]), Perceptions of Legitimacy of Need for Academic Accommodations $($ LNAA $)\left(F(1,855)=29.084, \mathrm{p}<.001, \mathrm{~h}^{2}{ }_{\mathrm{p}}\right.$ $=.033$, which reflects a small effect size[29]), Provision of Accommodations for the Exam Experience (PAE) $(F(1,833)$ $=11.912, \mathrm{p}<.01, \mathrm{~h}^{2}{ }_{\mathrm{p}}=.014$, which reflects a small effect size[29]), and Reasonableness of Special Accommodation Considerations in the Overall Academic Experience (RSCO) $\left(F(1,833)=6.253, \mathrm{p}<.05, \mathrm{~h}^{2}{ }_{\mathrm{p}}=.007\right.$, which reflects a small effect size[29]). In all identified scenarios, female responses were more favorable than male responses with PFAP and LNAA representing the greatest significance.

With respect to the Year in School demographic, significant differences were only identified within the
Perceptions of Fairness of the General Accommodation Process (PFAP) subsection $\left(\mathrm{F}(3,886)=3.149, \mathrm{p}<.05, \mathrm{~h}^{2}{ }_{\mathrm{p}}\right.$ $=.011$, which reflects a small effect size[29]). For this subsection, Juniors were identified as having a significantly more favorable response than First-Year students after a Scheffe post-hoc analysis. No other significant differences were identified. Previous works that focused on this demographic suggested one of two scenarios: (1) year in college does not appear to positively or negatively influence attitudes toward disability or (2) older students appear to have more positive attitudes toward students with disabilities in comparison to younger college students. Overall, this research project appears to have identified with both scenarios.

For the College/School of Major (the Student Majors) demographic, no significant differences were identified during this analysis. The lack of differences may have been due to the manner in which the colleges/schools were arranged by category in order to match the different programs at the two universities utilized in this investigation. Differences in overall campus cultures may have also lead to blending of attitudes.

With respect to the Degree of Contact demographic, significant differences were identified within subsections Provision of Accommodations for the Exam Experience (PAE) $\left(F(4,831)=5.085, \mathrm{p}<.001, \mathrm{~h}^{2}{ }_{\mathrm{p}}=.024\right.$, which reflects a small effect size[29]) and Reasonableness of Accommodations in the Classroom Experience (RAC) ( $F(4$, $831)=4.007, \mathrm{p}<.01, \mathrm{~h}_{\mathrm{p}}^{2}=.019$, which reflects a small effect size[29]). For both PAE and RAC, a Scheffe post-hoc analysis noted that there was a significant difference identified between students reporting very frequent contact and minimal contact. Students claiming very frequent contact had more favorable responses. In addition, students identifying themselves as having very frequent contact with persons with disabilities had significantly more favorable responses than students reporting occasional contact for the PAE survey items. A limitation of this demographic is that students were asked to report something subjective. For other demographics, students identified with a specific concrete category. Many students may not have considered their level of contact with people with disabilities previously. Furthermore, the nature of this research focused on hidden disabilities. With respect to the higher education setting, some students without disabilities may have had more contact with students with disabilities in the academic environment than realized.

When utilizing one-way ANOVAs to compare the six survey subsections against private and public undergraduate students within the higher education setting demographic, significant differences were identified within subsections of Perceptions of Legitimacy of Need for Academic Accommodations $($ LNAA $)\left(F(1,856)=6.324, \mathrm{p}<.05, \mathrm{~h}^{2}{ }_{\mathrm{p}}\right.$ $=.007$, which reflects a small effect size[29]), Provision of Accommodations for the Exam Experience (PAE) $(F(1,834)$ $=6.560, \mathrm{p}<.05, \mathrm{~h}_{\mathrm{p}}^{2}=.008$, which reflects a small effect size[29]), Reasonableness of Accommodations in the 
Classroom Experience $(\mathrm{RAC})(F(1,834)=34.205, \mathrm{p}<.001$, $\mathrm{h}_{\mathrm{p}}^{2}=.039$, which reflects a small effect size[29]), and Reasonableness of Special Accommodation Considerations in the Overall Academic Experience (RSCO) $(F(1,834)=$ 4.559, $\mathrm{p}<.05, \mathrm{~h}_{\mathrm{p}}^{2}=.005$, which reflects a small effect size[29]). For LNAA, the private student response was more favorable. The public student response was found to be more favorable for all remain ing subsections, which were all three subcategories within the specific accommodation survey section. Thus, students at the public university appeared to be more accepting of the actual accommodations that students with disabilities receive in the academic setting when compared to the students at the private university used in this research.

\subsection{Qualitative Findings}

The final survey item invited students to offer comments on perceived campus feelings toward academic accommodations and/or students with disabilities. Of the 532 comments received, 243 were deemed to be positive in tone while another 246 were neutral in attitudes. Only 43 student comments were openly negative toward students with disabilities and/or the academic accommodation process.

Student comments revealed several themes. A theme was established if at least 30 comments could be associated with it. The most common themes were listed and then remarks were organized by matching theme. So me comments did not fall within any of the listed themes while other remarks were matched with more than one theme. The six primary themes identified with frequency count of comments pertaining to theme in parentheses were: Accommodations Not Discussed/Noticed (182), Accommodations Create Unfair Advantages (132), Maintain College Expectations (64), If Done for One, Then Do for All (58), LD vs. ADD (48) and What About the Real World? (35).

A degree of subjectivity did exist in the theme assortment exercise. Every attempt was made to evaluate comments based only on what was written within the comment box rather than try to interpret what the student may have been implying. Effort was made to categorize only those comments that explicitly addressed one of the identified themes. What follows is an explanation of each category along with comments associated with the category. Readers will take note some overlap across categories when reading the student statements.

\subsection{Accommodations Not Discussed/Noticed}

Slightly over a third of the comments (34\%; 182 of 532) specifically referenced not having discussed the accommodation issue with peers or having noticed the accommodation process in operation. One sample comment from this category follows.

In general, I do not think college students care about what accommodations are given to students with LD and ADD. I would say the average student does not even know who has learning disabilities in his or her classroom. I would not consider it to be a large problem in the college setting. Students have thems elves to worry about.

\subsection{Accommodations Create Unfair Advantages}

Some students mentioned a belief that academic accommodations create unfair advantages. What constituted "unfair" was somewhat individually defined. If the student perceived the accommodation place the student him- or herself at a disadvantage, perhaps because the very accommodation would also benefit that student without a disability, then the accommodation was deemed unfair. In some cases, students went past an individual perspective and viewed the accommodation from a more holistic college perspective. Unfair accommodations were also defined as something that modified the program or perhaps resulted in a modification of expectations for the student with a disability in comparison to the students without disabilities. Students without disabilities further expressed concern when the accommodations were used by students with disabilities in place of hard work and effort or as a way of "cheating the system.”

By student definition, the concept of unfair accommodations overlaps with the next two themes to be discussed, "Maintain College Expectations” and "If Done for One, Then Do for All." A comment from this theme is below.

I think students in campus understand the different needs that kids with disabilities have, and they also understand that they need more help in courses. However they find it somewhat unfair in some cases. They think some of the help they get is unfair and that they should not receive that much help. I think that yes they do need more resources than us, but that those resources shouldn't be extremely different or unfair.

\subsection{Maintain College Expectations}

If the accommodations provided alter the college student expectation in some manner, such as different course requirements or different assignments, then some of the students stated that such change went beyond a reasonable limit and was in essence "unfair." A few of the comments were particularly targeted toward the accommodations listed in the portion of the survey entitled Reasonableness of Special Accommodation Considerations in the Overall Academic Experience. As mentioned in the survey, the list of offered accommodations varies from university to university with the implication that certa in acco mmodations may not be offered at the college where the student responding to the survey attends. Yet the thought of such accommodations led to some lively responses from students. One such comment is provided below.

It depends on the disability in question. And it depends on the extent of extra help the pers on is getting. The only reason I feel negatively toward academic accommodations like different course requirements is that it cheapens the degree I'm working at getting if someone else can do half the work and still call themselves a bachelors of

\subsection{If Done for One, Then Do for All}


Some of the students asked why something available to students with disabilities were not also available to students without disabilities. Students with equity concerns seemed to express a desire for a support if that support was deemed to be something that would help the student him- or herself. A comment taken from this theme follows.

No one student, or group of students, publicly speaks negatively about students with leaming disabilities. However, I am sure that some do feel that leaming disabilities are loosely diagnosed and that these conditions are treated with medicines. Both of these facts should encourage the university to keep classrooms the same for all students.

\subsection{LD vs. ADD}

Some students commented that they perceive a difference between the two disabilities of focus in this research, which were learning disabilities and ADD/ADHD. A few students stated that they had a hard time answering the survey questions because they would have answered differently if the disabilities were separated with participants responding to each survey item once for students with learning disabilities and a second time for students with ADD/ADHD as opposed to being lu mped together within each survey item as was designed. Substantial time was spent debating this issue before opting to combine the disabilities. On one hand, great value was realized in separating the two disabilities but there was concern that doubling the length of the survey would discourage students without disabilities from responding. In addition, there was question as to how many students with basic, average knowledge about disabilities would categorize learning disability and attention deficit dis order differently.

When students specifically commented on the disabilities in their qualitative survey comments, the responses were placed in this theme. All such student responses expressed more understanding, and perhaps sympathy, for students with learning disabilities while students with ADD/ADHD were viewed with skepticism while the accommodations received for this disability were questioned. Part of the uncertainty with ADD/ADHD had to do with the perceived ease of diagnosis and/or the role of medication in eliminating the effects of attention deficit disorder. There were also remarks suggesting that anyone could get an attention deficit disorder diagnosis. A comment pertaining to this theme follows.

I think most students are oblivious to the accommodation process. I don't think many students know others that need academic accommodations. However, I think students are more accepting of students with a LD rather than students with ADD. The stigma with ADD is that prescription drugs can be used to help, but with LD, drugs are not available.

\subsection{What about the Real World?}

Some students questioned the reasonableness of giving students with disabilities accommodations at the college level because of believed perceptions that such accommodations are not available "in the real world." While some of the remarks may have come across as condescending, some of the students without disabilities may have intended to consider what they perceived to be the best interest of students with disabilities. For this theme, a major issue focuses not on what students without disabilities do not receive but rather what these particular students believe students with disabilities lack when using accommodations, particularly as it relates to being prepared for life after college. The extent to which the receipt of accommodations may or may not benefit students with disabilities specifically with respect to real world job performance is beyond the scope of this study. However, some students without disabilities felt that students with disabilities may be hurting their real world advancement by using accommodations in the higher education setting. A comment focused on this theme is below.

If they want to compete against students without problems on a GPA and honor level, they should be held to the same academic rigors. If they need medicine or accommodations to perform it should be noted on their transcript so that an employer or graduate school knows what they are getting. The Real world doesn't give extra time and college is real world preparation therefore it logically follows that college wouldn't give ext ra time (or other advantages).

\section{Discussion and Recommendations}

Some students with hidden disabilities are very hesitant to use academic accommodations because doing so could potentially disclose their situation to their classroom peers. Olney and Brockelman[30] stated that students with disabilities use perception management tactics when navigating the college environment. They have a tendency to feel that they need to either struggle through a class without accommodations or use accommodations but risk being stigmatized by students without disabilities. As a result, the students cautiously determine with whom they will share informat ion about their dis ability.

While students with disabilities may have these preconceived notions, the data collected from this research calls into question the accuracy of these beliefs. Almost one third of the qualitative comments collected specifically stated that students without disabilities were not aware of accommodation use by students with disabilities. Many other comments alluded to the same unconcerned point of view but could not be conclusively categorized as such. As a result, students with disabilities may be farther removed from the spotlight than realized.

Campus disability service providers can reference this information when students with disabilities express these concerns during office consultations. This information also could be usefulduring campus visits and orientations prior to the student starting the college experience. It may help lessen student fears early enough in the process so that the student with a disability makes the choice to use accommodations 
from the outset rather than waiting until a potential "academic hole" has been dug with grades too low from which to successfully recover.

In addition, over $80 \%$ of the qualitative comments that did discuss accommodations were neutral or positive on the matter for the most part. Displeasure with accommodations was recognized when accommodations were perceived to cross a threshold past the point of what the student defined to be fair. While the researchers cannot say conclusively with the comments provided, they questioned whether students without disabilities lack knowledge about the accommodation process, specifically the reasons behind the accommodations. Based on the data collected, it is as though the students know the "what" (the accommodation process) but not necessarily the "why" behind it. If more students knew the foundational reasons for accommodations, would more students be in support of the process?

Initially, the researchers postulated a need for disability service providers to generate greater awareness of the accommodation process under the assumption that students without disabilities may not perceive accommodations to be unfair if the intent behind the process was known. But the investigators also recognized the percentage of students without disabilities who admittedly were not aware of the process, which appears to benefit students with disabilities. Students with disabilities may be able to blend in with the crowd more easily than realized, which is what many students with disabilities state that they desire. Perhaps a campaign to increase accommodation knowledge and awareness, such as a group or dedicated week focusing on "Disability Allies/Awareness", subsequently do more harm than benefit if students without disabilities learn enough to better recognize students who do use accommodations. Would students with disabilities lose the opportunity to remain undisclosed as a result? How would most students without disabilities respond to this information and possible subsequent greater recognition of interaction with students with disabilities?

McCarthy[31] and Gibson[32][33] promoted identity development and self-advocacy skill development in students with disabilities. By helping students with disabilities to recognize, to accept, and to speak about their needs, students can become better integrated with the world around them[34]. Such skills may give the students with disabilities more confidence to ask for acco mmodations and to support their need for accommodations rather than worry ing about what students without disabilities may think when they gain an awareness of the accommodation process.

\subsection{Implications for Action within the General Academic Classroom Setting}

As shown through this study, students without disabilities do not want students with disabilities to have an easier road to travel en route toward a degree. The hope seems to be that the academic journey is as close to universally equivalent as possible. A concept that has been gaining traction in recent years is the idea of Universal Instructional Design (UID). UID specifically addresses what many students without disabilities were suggesting, though not specifically, through the responses provided for this survey and should perhaps be something that colleges should consider. UID recognizes the fact that teaching is not a "one size fits all" activity[35][36]. When implemented, course instructors build components into the course that recognize the unique learning styles of all students of all abilities in the classroom. UID courses offer a variety of ways to present information (lectures, visual slides, video presentations, class discussion, small group work, etc.) and encourages an appropriate balance of different techniques while also giving different opportunities for students to demonstrate knowledge[37][35][38]. Not only would students with disabilities benefit, but so would students without disabilities. Furthermore, many of the perceived inequities of the accommodation process, and maybe the associated attitudes formed as a result, could perhaps be eliminated if UID was done well. As Burgstahler[37] noted, "universally designed instruction is welcoming, accessible, and inclusive for all qualified students (e.g., they meet the prerequisites) to take a course without giving unfair advantage to anyone."

\section{Conclusions}

How students without disabilities perceive students with $\mathrm{ADD} / \mathrm{ADHD}$ and learning disabilities in the college academic environment based on students' use of academic accommodations was the primary focus of this study. Based on the data analyzed, perceptions of students without disabilities were mostly neutral and/or positive. Further, students without disabilities seemed to have greater acceptance of students with learning disabilities than of students with ADD/ADHD based on the collective qualitative comments received.

Data also revealed that over one-third of students without disabilit ies reported lack of awareness of the accommodation process, which suggested that students with disabilities may not necessarily be in the spotlight with respect to receiving and using academic accommodations in the classroom. While many students without disabilities appeared to support or at least did not express concern about the concept of the accommodation process when recognized, limits to what was tolerated within the process existed. Many students without disabilities did not openly support all facets of the accommodation system. Rather, support was only given so long as the accommodations provided were not viewed to be something that adversely impacted the student without a disability in some manner. How an accommodation might adversely impact a student without a disability was individually defined. The variability of what was and what was not accepted suggested a degree of comple xity regarding attitudes toward the acco mmodation process and the students with disabilities who use them, as reflected in this concluding student comment: 
I believe that generally, the student population is understanding to those with learning disabilities or ADD. Furthermore, I believe that the student population understands and approves of the use of academic accommodations for those individuals. However, there is a certain extent in which academic accommodations begin to be discriminatory to[students without ADD or learning disabilities], such as when those students: are given alternate assignments or exam formats, are given access to certain accommodations, which could reasonably help an individual[without ADD or a learning disability], or are given leniency in complet ing specified course requirements. I believe the general student population realizes the need for academic accommodations to ensure the success of[individuals with] ADD or learning disabilities; however, these accommodations should not extend so far that they become discriminatory to individuals [with disabilities].

* Survey tool may be requested from authors

\section{REFERENCES}

[1] Stalcup, R. J., \& Freeman, M. A. (1980). Serving the learning disabled student in the community college. Community College Frontiers, 8, 36-38.

[2] Olsen, G. (1981). Handicapped student services: Whose resp onsibility? NASPA Journal, 19, 45-49.

[3] Guildroy, J. (1981). The learning-disabled college applicant. College Review Board, 120, 29-30.

[4] Marion, P. B., \& Iovacchini, E. V. (1983). Services for handicapped students in higher education: An analysis of national trends. Journal of College Student Personnel, 24, 131-138.

[5] Vogel, S. A. (1983). On developing LD college programs. Journal of Learning Disabilities, 15, 518-528.

[6] Sicoli, M. L. C. (1985). College students with LD: Support systems and programs. Journal of Reading, Writing, and Learning Disabilities International, 1, 59-62.

[7] Strichart, S. S., \& Mangrum, C. T., II (1986). College for the learning-disabled student: A new opportunity. Journal of Reading, Writing, and Learning Disabilities International, 2, 251-266.

[8] Hoy, C., \& Gregg, N. (1986). Learning disabled students: An emerging population on college campuses. Journal of College Admissions, 112, 10-14.

[9] Robinson, A. (1986). Access to higher education for learning disabled students. Washington, US: Disabilities and Gifted Education. (ERIC Document Reproduction Service No. ED355750).

[10] Nelson, R., \& Lignugaris-Kraft, B. (1989). Postsecondary education for students with learning disabilities. Exceptional Children, 56, 246-265.

[11] Madaus, J. W. (2000). Services for postsecondary students with disabilities: A Historical perspective. Journal of Postsecondary Education and Disability, 14, 4-21.
[12] Raue, K., and Lewis, L. (2011). Students With Disabilities at Degree-Granting Postsecondary Institutions (NCES 2011-018). U.S. Department of Education, National Center for Education Statistics. Washington, DC: U.S. Government Printing Office.

[13] Rehabilitation Act of 1973, Sec 504. Retrieved August 6, 2011 from http://www.dotcr.ost.dot.gov/documents/ycr/REH ABACT.HTM

[14] Americans with Disabilities Act of 1990, 42 U.S.C. 12101 et seq. Retrieved August 6, 2011, fromhttp://www.ada.gov/pub s/ada.htm

[15] Ash, A., Bellew, J., Davies, M., Newman, T., \& Richardson, L. (1997). Everybody in? The experience of disabled students in further education. Disability \& Society, 12, 605-621.

[16] Snyder, T., and Dillow, S. (2010). Digest of Education Statistics 2009 (NCES 2010-013), (Table 231). National Center for Education Statistics, Institute of Education Sciences, U.S. Department of Education. Washington, DC.

[17] Ajzen, I. (1988). Attitudes, personality, and behavior. Chicago: The Dorsey Press.

[18] Henderson, C. (2001). College freshman with disabilities, 2001: A biennial statistical profile. Washington, DC: American Council of Education, HEATH Resource Center.

[19] Jarrow, J. E. (1993). Beyond ramps: New ways of viewing access. New Directions for Student Services, 64, 5-16.

[20] Barga, N. K. (1996). Students with learning disabilities in education: Managing a disability. Journal of Learning Disabilities, 29, 413-421.

[21] Brinckerhoff, L. C., Shaw, S. F., \& McGuire, J. M. (1992). Promoting access, accommodations, and independence for college students with learning disabilities. Journal of Learning Disabilities, 25, 417-429.

[22] Jones, G. C., Kalivoda, K. S., \& Higbee, J. L. (1997). College students with attention deficit disorder. NASPA Journal, 34, 262-274.

[23] Kravets, M. (2006). Hidden disabilities: Another diverse population. Journal of College Admission, 190, 18-25.

[24] Fichten, C. S. (1986). Self, other and situation-referent automatic thoughts: Interaction between people who have a physical disability and those who do not. Cognitive Therapy and Research, 10, 571-587.

[25] Lyons, M., \& Hayes, R. (1993). Student perceptions of persons with psychiatric and other disorders. The American Journal of Occupational Therapy, 47, 541-548.

[26] Yuker, H. E. (1994). Variables that influence attitudes toward people with disabilities: Conclusions from the data. In D. S. Dunn (Ed.), (1994). Psychosocial perspectives on disability[Special issue]. Journal of Social Behavior and Personality, 9, 3-22.

[27] Upton, T. D., Harper, D. C., \& Wadsworth, J. (2005). Postsecondary attitudes toward persons with disabilities: A comparison of college students with and without disabilities. Journal of Applied Rehabilitation Counseling, 36, 24-31.

[28] Feinberg, L. B. (1967). Social desirability and attitudes toward the disabled. Personnel and Guidance Journal, 46, $375-381$. 
[29] Huck, S. W. (2008). Reading statistics and research. Boston: Pearson Allyn \& Bacon Merrill.

[30] Olney, M. F., \& Brockelman, K. F. (2003). Out of the disability closet: Strategic use of perception management by select university students with disabilities. Disability \& Society, 18, 35-50.

[31] McCarthy, D. (2007). Teaching self-advocacy to students with disabilities. About Campus, 12, 10-16.

[32] Gibson, J. (2006). Disability and clinical competency: An introduction. The California Psychologist. 39. 6-10.

[33] Gibson, J. (2011). Advancing Care to Clients with Disabilities through Clinical Competency. The California Psychologist, 44(4). 23-26.

[34] Bryan, A., \& Myers, K. (2006). Students with disabilities: Doing what's right. About Campus, 2(4), 18-22. San Francisco: Jossey-Bass.

[35] Higbee, J. L. \& Goff, E. (Eds.), (2008). Pedagogy and student services for Institutional transformation: Implementing universal design in higher education. Minneapolis: Center for Research on Developmental Education and Urban Literacy, College of Education and Human Development, University of Minnesota.

[36] Myers, K. A., Wood, J. N., \& Pousson, M. (2007). Universal instructional design: A community relations plan for K-12 success. Journal of School Public Relations, 28, 251-270.

[37] Burgstahler, S. E. (2008). Universal design of instruction: From principles to practice. In S. E. Burgstahler \& R. C. Cory (Eds.), Universal design in higher education: From principles to practice. Cambridge, Massachusetts: Harvard Education Press.

[38] Johnson, D.M., \& Fox, J. A. (2003). Creating curb cuts in the classroom: Adapting universal design principles to education. In J. L. Higbee (Ed.), Curriculum transformation and disability: Implementing universal design in higher education. Minneapolis: Center for Research on Developmental Education and Urban Literacy, General College, University of Minnesota. 